\title{
Biomonitoring: New Approaches and Preliminary Assessment of Large-Scale Event Impacts
}

\author{
Isabella C. Bordon ${ }^{1} \cdot$ Rachel Ann Hauser-Davis ${ }^{2}$
}

Received: 12 May 2021 / Accepted: 13 May 2021 / Published online: 24 May 2021

(c) The Author(s), under exclusive licence to Springer Science+Business Media, LLC, part of Springer Nature 2021

Motivated by environmental disasters that have recently occurred in Latin America, the Special Issue "Biomonitoring: New approaches and preliminary assessment of large-scale event impacts" joins recent manuscripts about biomonitoring, focusing on: (1) new monitoring approaches for classical (such as oil, metals and polycyclic aromatic hydrocarbons) and emerging contaminants such as pharmaceutics, macro, micro and nanoparticles; and pesticides, among others; (2) preliminary evaluations just after largescale outflows, in order to assess first impacts. Among many great studies, outstanding manuscripts were selected and are compiled in this issue. Readers and researchers will find integrated discussions on the effects of contaminants from anthropogenic activities on endangered species, mainly in environments undergoing highly selective pressures. The prospection of biomonitors to confirm the impact of these contaminants in rare and fragile ecosystems (such as the Amazon) are also discussed. Both general concepts were considered, including specific issues of major biological groups extending beyond conventional systems and comprising several sentinel species regarding human activities.

Dr. Rachel Ann Hauser-Davis and myself, Dr. Isabella C. Bordon, were incredibly honored by the Editor-in-chief's invitation to edit this issue and we would like to thank all of the authors for their support and confidence. We hope that this content contributes to the improvement of Biomonitoring efforts and highlights the usefulness of this powerful tool for ecotoxicological and conservation approaches.

Enjoy the reading!

Publisher's Note Springer Nature remains neutral with regard to jurisdictional claims in published maps and institutional affiliations.
Isabella C. Bordon

isabella.bordon@gmail.com

1 Instituto de Ciências Biomédicas Aff1, Universidade de São Paulo - USP, São Paulo, SP, Brazil

2 Fundação Oswaldo Cruz - Fiocruz, Rio de Janeiro, RJ, Brazil 